\title{
Molecular dynamics simulation of nanoconfined ethanol-water mixtures
}

\author{
Farkhondeh Mozaffari*, Mina Zeraatgar
}

Department of Chemistry, College of Sciences, Persian Gulf University, Bushehr 75168, Iran

*To whom correspondence should be addressed. Email: mozaffarif@pgu.ac.ir

Tel: ++98-77-33422223

Fax: ++98-77-33441494 


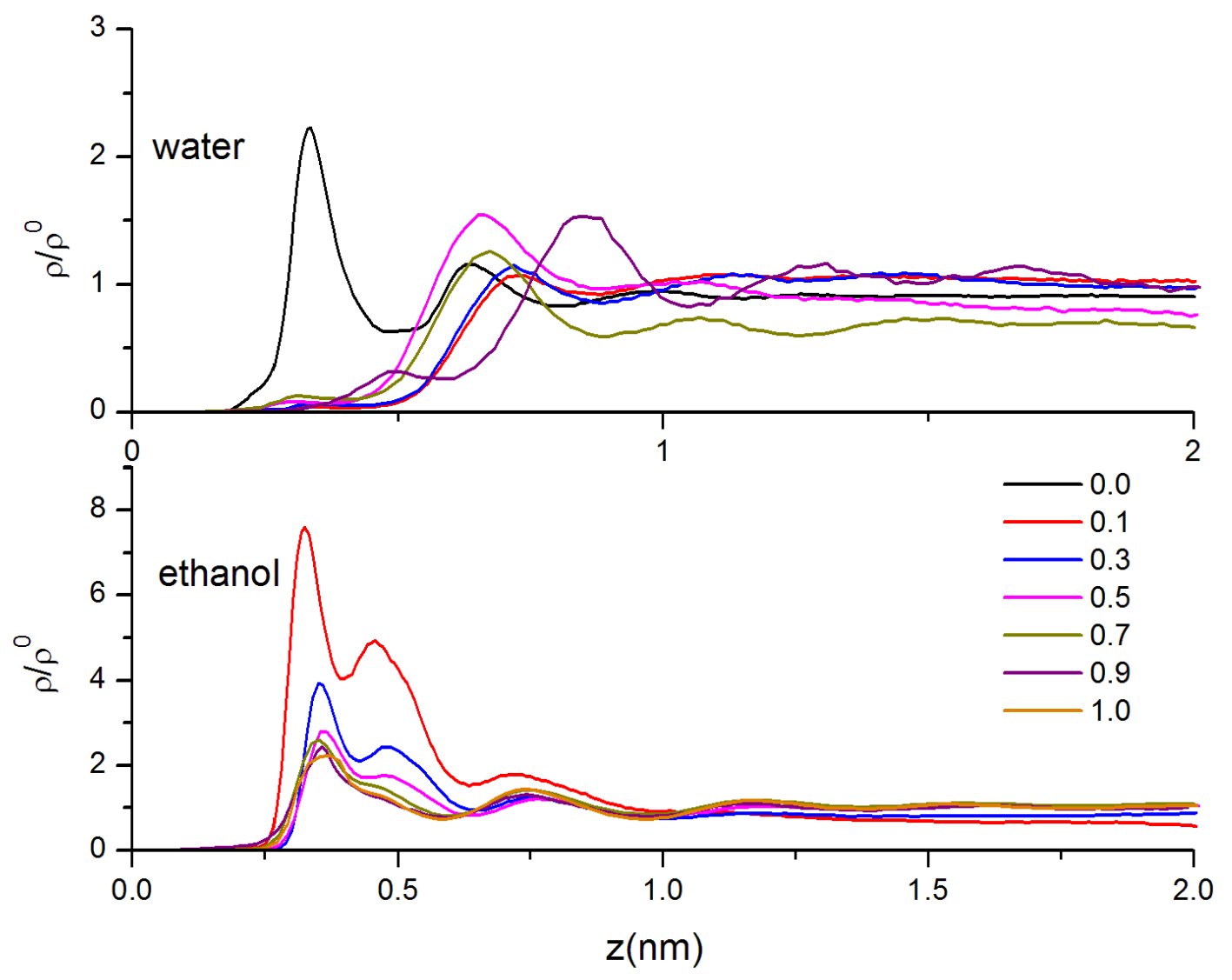

Figure S1. Number density profiles $(\rho)$ of water and ethanol confined between graphene surfaces of system A in different ethanol mole fraction (ethanol mole fraction indicated in legend), which is normalized with the corresponding quantity for a sample of bulk mixture $\left(\rho^{0}\right)$. Because of the symmetry of the simulation box and large pore width, the density profiles in the vicinity of one surface is shown. 


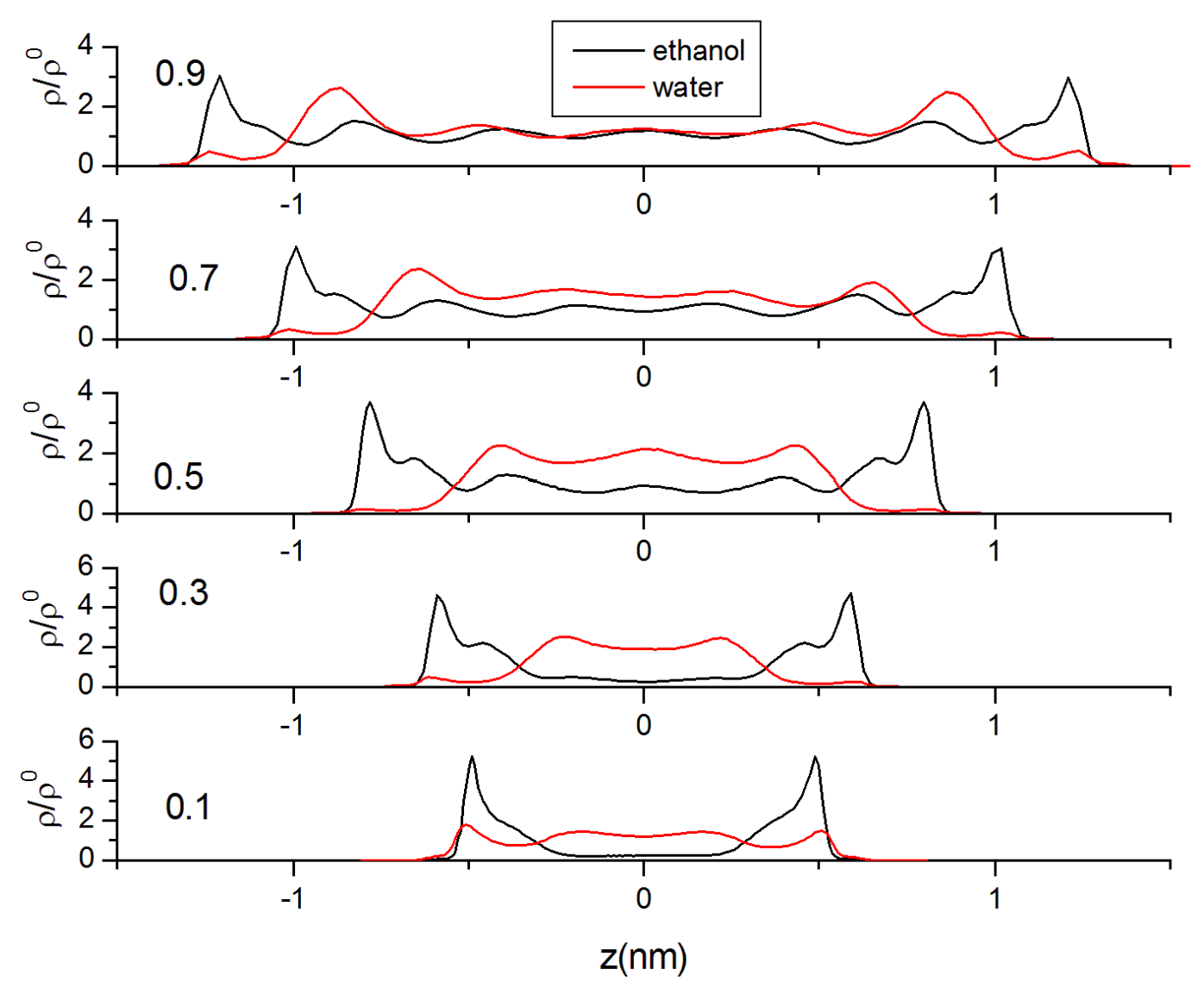

Figure S2. Number density profiles $(\rho)$ of water and ethanol confined between graphene surfaces of system B in different ethanol mole fraction (ethanol mole fraction indicated in legend), which is normalized with the corresponding quantity for a sample of bulk mixture $\left(\rho^{0}\right)$. 


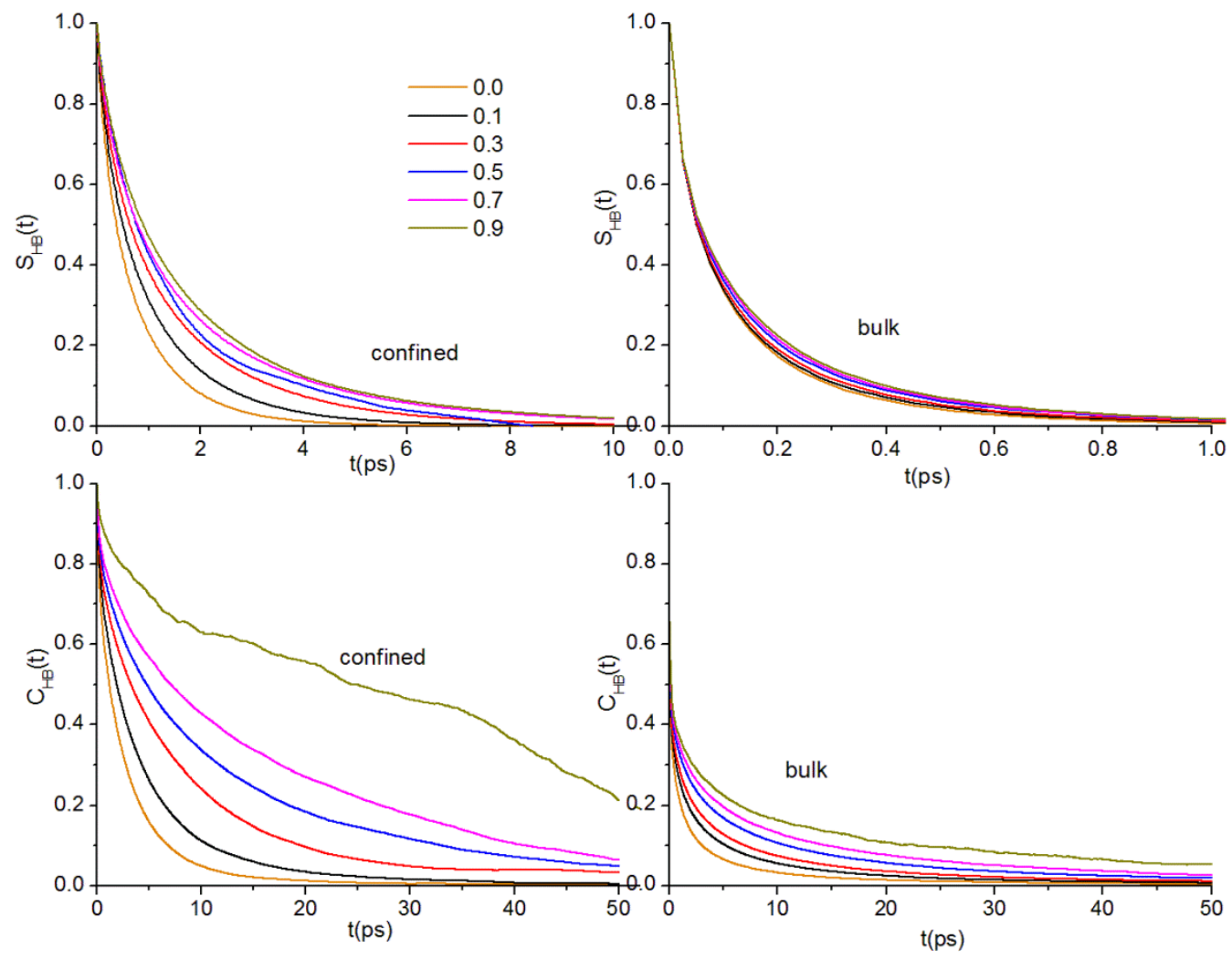

Figure S3. The continuous hydrogen bond correlation function $\left(\mathrm{S}_{\mathrm{HB}}(\mathrm{t})\right)$ and the intermittent hydrogen bond correlation function $\left(\mathrm{C}_{\mathrm{HB}}(\mathrm{t})\right)$ of $\mathrm{H}_{2} \mathrm{O}-\mathrm{H}_{2} \mathrm{O} \mathrm{HBs}$ in $0.3 \mathrm{~nm}$ thick slab $(0.6<\mathrm{d}<0.9)$ parallel to surface for confined system $\mathrm{C}$ and bulk, ethanol mole fraction indicated in legend. 


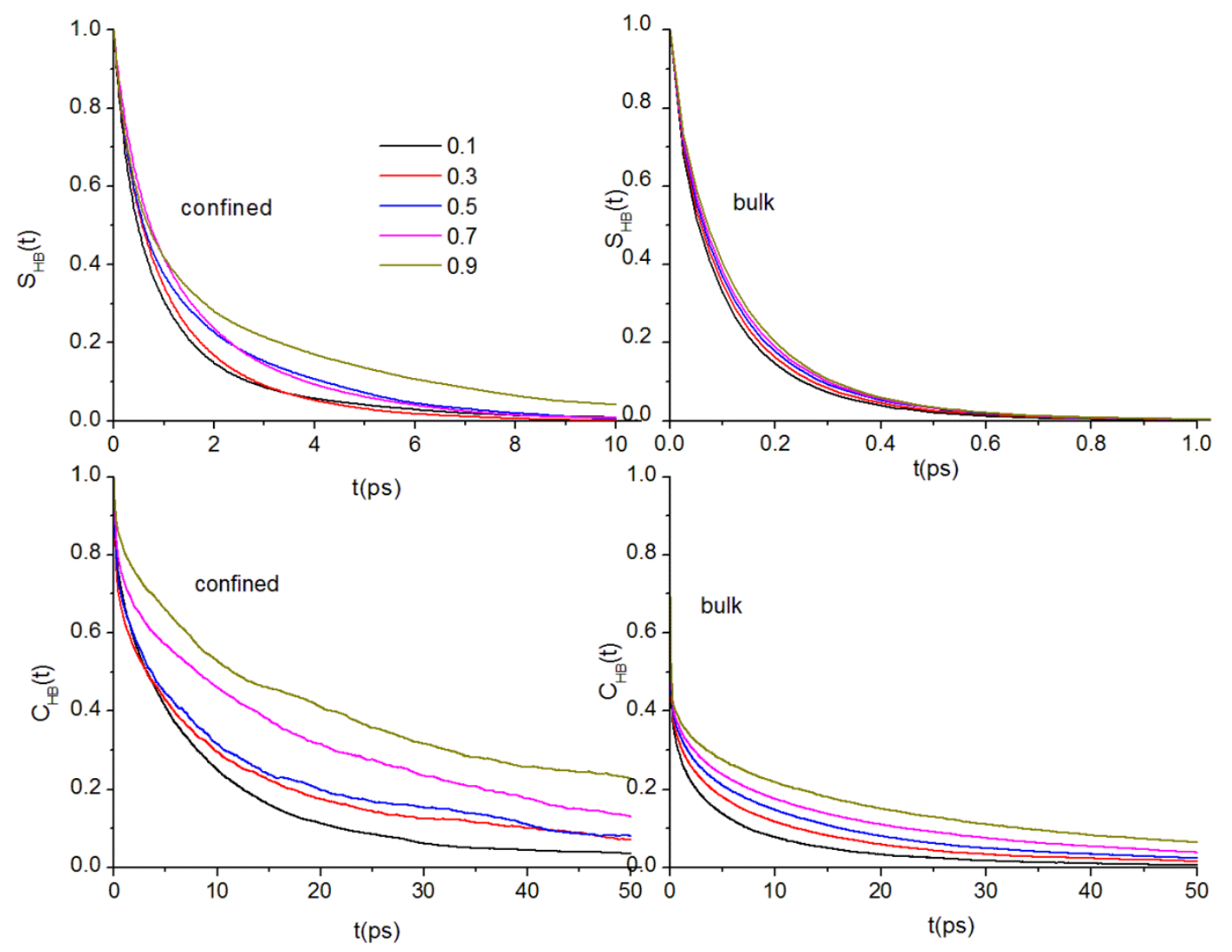

Figure S4. The continuous hydrogen bond correlation function $\left(\mathrm{S}_{\mathrm{HB}}(\mathrm{t})\right)$ and the intermittent

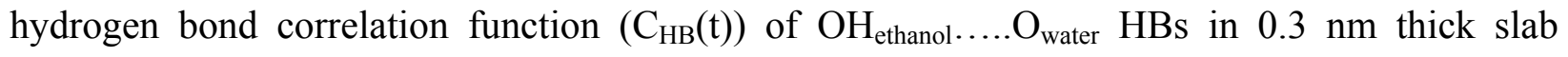
$(0.3<\mathrm{d}<0.6)$ parallel to surface for confined system $\mathrm{C}$ and bulk, ethanol mole fraction indicated in legend. 